$\begin{array}{ll}\text { Titel: } & \text { Die krisis van die afwesige gees } \\ \text { Outeur: } & \text { C.S. de Beer } \\ \text { Pretoria: } & \text { Malan Media (2016) } \\ \text { Bladsye: } & 316 \text { bladsye } \\ \text { ISBN: } & 978-1-920335-55-7\end{array}$

\title{
Om weer te begeester
}

Om iets oor hierdie merkwaardige boek te sê, is moeilik sonder om eers iets oor die skrywer en my eie pad met hom te sê - as 'n skrywer sowel deur sy idees as deur sy leefwyse so 'n bepalende en steeds vormende invloed op 'n leser van sy boek uitoefen, kan dit kwalik anders.

Dit is so dat die geskiedenis die verhaal van die oorwinnaars is, maar miskien werk die geskiedenis van die filosofie anders. Miskien is die geskiedenis van die filosofie die verhaal van die waardige verloorders wie se waarde veel groter as dié van 'n militêre of magsoorwinning is. Luister na Sokrates se woorde aan die lafhartige, magsdronk jurie wat hom, die gewete en geestesversorger van Athene, ter dood veroordeel omdat hy die stad teen haar eie onkunde wou beskerm:

Maar ek wil nou vir julle, my veroordelaars, die toekoms voorspel. Wanneer mense op die punt staan om te sterf, maak hulle graag voorspellings en ek is nou by dié punt. Ek sê nou, menere wat my ter dood veroordeel het, dat straf vir die onreg teenoor my onmiddellik na my dood oor julle gaan kom, baie erger as die doodstraf wat julle vir my bepaal het. Ja, julle het dit nou gedoen met die gedagte dat julle nie rekenskap van julle lewens hoef te gee nie, maar dit sal net mooi in die teendeel uitdraai, soos ek dit uitspel. Die wat van julle rekenskap gaan eis, sal meer wees as tot nou toe. (Plato, Verdediging van Sokrates uit Grieks vertaal deur Piet Boshoff, Publishing World SA: plek van publikasie nie aangedui nie, 2015, p.77)

Vyf-en-twintig eeue later word Sokrates se profesie steeds vervul soos wat nuwe ontdekkers van sy denke telkens weer saam met hom vir die filosofie teen onreg en magsmisbruik kies. In die Afrikaanse wêreld sal 'n Marthinus Versfeld en 'n Johan Degenaar langer onthou word as die versmoorders van die gees waarteen hulle met die weerlose stem van die rede in 'n tyd van domheid en onreg opgestaan het, die woord suiwer gevoer het vanuit die marges teenoor die sentrum. 'n Mens kan dit ook van C.S. (Fanie) de Beer in die vooruitsig stel.

In die geslag waarin hy gebore is, was die mees gesogte beroepe dié van landbouer, predikant of onderwyser. Vir praktiese doeleindes is hy in al drie hierdie beroepe opgelei, en het hy twee beoefen. Nadat hy eers landbou studeer, studeer hy teologie met filosofie as een van sy vakke. Hy betree die bediening, maar begeef hom uiteindelik in die akademie, wat hy op 'n heel sonderlinge wyse beoefen. In die veelbewoë jaar 1976 te midde van die kultuurboikot gaan studeer hy onder Paul Ricœur. Getrou aan Ngugi wa'Thiõngõ se oproep aan Afrikadenkers om kennis elders versamel plaaslik en in die plaaslike tale tuis te bring, doen De Beer dit nou haas veertig jaar, waarvan die boek hier onder bespreking 'n hoogtepunt is.

Dit is egter vanaf die 1980's wat De Beer se loopbaan die boeiendste wendinge ondergaan. Eers word hy uit 'n akademiese pos gehou omdat hy nie deel vorm van die establishment nie. Soos hy self in hierdie boek terloops noem, word hy weens 'n onvoorsiene sameloop van omstandighede besadig voortgaande op sy eensame denkweg eers professor in Inligtingkunde en later hoof van die betrokke departement. En toe, met formele aftrede in die ouderdom van 65 begin die belangrikste en skeppendste deel van sy loopbaan as denker - hy word naamlik 
buitengewone professor in Inligtingkunde aan die Universiteit van Pretoria, en bly dit tot op die rype ouderdom van 80 .

Dog, nog is't het einde niet. De Beer publiseer in 1988 die titelartikel van hierdie boek in die RGN Navorsingsbulletin. Met groot dringendheid beskryf hy wat die verwaarlosing van die gees - sy Afrikaans vir Aristoteles se nous - aan ons en ons wêreld doen, maar geen haan kraai daarna nie. Tussen die reëls kan die leser aflei dat De Beer te midde van hierdie stilte half moedeloos die tema van die gees in ons tyd laat vaar het, 'n stem roepende in die woestyn van 'n land so gefikseer op die politiek en elitebelange dat die gees maar in die slag kon bly.

En toe, in 2006, kom die werk van Bernard Stiegler en die kring denkers om hom onder De Beer se aandag, spesifiek in die vorm van die klein boekie van Stiegler en andere, Réenchanter le monde: la valeur esprit contre le populisme industriel ("Om die wêreld te heropluister: die waarde van die gees teen die industriële populisme”). De Beer beskryf sy reaksie op hierdie boekie:

Ek kon dit nie glo nie: twintig jaar later is een baie belangrike hedendaagse filosoof, saam met kollegas van hom, besig om presies oor hierdie saak, die idee van die gees en geestelike waarde, te skrywe en omvangryke strategieë uit te werk ten gunste van die herwinning van geestelikheid en die erkenning van gees. Ten minste het dit my verseker, as ek na een van die geestesdokumente wat deel van ons erfenis is en vir baie nog kosbaar is mag verwys, dat as daar maar tien regverdiges in Sodom is, sal die stad gespaar bly (Gen. 18), dat daar nog hoop vir die mensheid is - nie omdat daar spesifieke persone is nie, maar omdat daar wel 'n groep van meer as tien is. Hierdie werk gee my vrymoedigheid om oor die idee van die gees te skrywe. (47-48)

De Beer se kennismaking met die werk van Stiegler word so begeesterend dat hy in die laaste tien jaar van sy formele loopbaan nie minder nie as twaalf van die veertien bydraes waaruit hierdie boek bestaan, skryf. Alvorens die verskillende bydraes hieronder kortliks behandel word, eers enkele algemene opmerkings oor die boek.

In die eerste plek moet die poëtiese skryfstyl van die werk uitgesonder word. De Beer is afgesien van Heidegger, wat self 'n poëtiese skrywer was, merendeels deur Franse denkers van die laaste vyf dekades en selfs meer beïnvloed. Dit is alombekend dat die Franse filosofiese skryftradisie besonder poëties en literêr is, veel minder stelselmatig as soveel van die filosofie wat in Duits of Engels geskryf word. Dit is verfrissend dat De Beer dieselfde styl in hierdie werk handhaaf, wat daaraan 'n besondere persoonlike tekstuur gee wat die leser nie onaangeraak laat nie.

In die tweede plek handhaaf De Beer in navolging van een van sy groot helde, Michel Serres, 'n akritiese styl. De Beer is veel meer ingestel op die raakpunte en ooreenkomste tussen 'n groot verskeidenheid denkers oor die gees, as op die verskille tussen hulle. Die beste omskrywing van skeppendheid wat ek ken, is om onverwagse verbande tussen oënskynlike uiteenlopende dinge te trek. Presies dit is wat De Beer dan ook hier doen deur soveel uiteenlopende denkers en skrywers so kragtig samespraak oor die gees van ons tyd te laat voer, net soos hy by meer as een geleentheid in die verlede denkers vanuit verskillende vakgebiede akrities oor brandende eietydse vraagstukke soos die gees kon begeester om saam met hom te dink en te skryf, onder meer as gasredakteur vir spesiale temanommers oor menslike geestelikheid in die Tydskrif vir Geesteswetenskappe.

In die derde plek slaag hy daarin om vanuit die Suid-Afrikaanse konteks met 'n groter konteks gemaklik in gesprek te tree. Hy help die leser om te sien hoe die dringende en dikwels uitmergelende vraagstukke van die Suid-Afrikaanse lewe, soos armoede en geweld, nie los te 
verstane is nie van breër geestelike vraagstukke van ons tyd waarvoor die ganse mensdom vandag te staan gekom het. Deurgaans word hierdie vraagstukke met volkome eerlikheid aangesny - dikwels in ontstellende besonderhede - maar nooit sonder om die hoop op iets beters te verloor nie, en nooit sonder om die leser daaraan te herinner dat elkeen van ons kan deelneem aan die herkultivering van die gees ten einde die wêreld te heropluister - De Beer se poëtiese term vir réenchanter wat die regte kontemplatiewe lewenshouding aan die herstel van die wêreld se luister verbind. Hiermee kan nou oorgegaan word tot 'n kortlikse behandeling van elk van die hoofstukke.

In die titelopstel uit 1988 diagnoseer De Beer die verlies aan die gees in die moderne wetenskap: "Sedert Galileo is die toegang tot kennis, die middele waardeur die natuur gedwing is om sy geheim bloot te lê, en die koninklike weg na wetenskaplike waarheid deur dade en handeling bereik, en nie deur kontemplasie en besinning alleen nie" (19, sy klem). Daarom, in aansluiting by Cornelius Castoriadis, is die krisis van die wetenskappe dat ondanks al die vordering met kennis ons nie die wesenlike probleme van die mensdom soos armoede, konflik en lyding oplos nie. 'n Merkwaardige insig: Juis omdat die oorheersende materialistiese paradigma van die moderne wetenskap die gees misken, kan dit nie die dringendste materiële probleme van ons tyd oplos nie.

Volgens De Beer moet die krisis van die wetenskap herlei word na die feit dat die aanname dat alles 'n rede moet hê self nie bedink en bevraagteken word nie. Dit is dan juis die taak van die denke om hierdie vraagstuk onder die loep te neem - waarmee De Beer aansluit by die grote Vico se siening van die filosofie as die metafisika, dit wil sê, daardie wetenskap wat aan elke wetenskap sy plek in die groter geheel moet toeken ten einde goeie wetenskapsbeoefening te verseker.

Vir De Beer gaan dit alles om die herstel van die gees in wetenskapsbeoefening - die gees as nous wat die totale geestelike aktiwiteit van die mens omvat. Hier verwys hy na die verwording van die eietydse akademie: "In hierdie bedrywige [akademiese] program, wat soms selfs angsvallig en koorsagtig verloop, word uit die oog verloor dat die beste, nuutste, mees blywende daad dikwels in oomblikke van geïsoleerde kontemplasie gebore word" (30). Hierteenoor pleit hy à la Vico vir die samehang en interafhanklikheid van verskillende wetenskaplike diskoerse oor 'n saak. En belangrik: Gebeur dit nie, sit ons met ideologie pleks van denke, oftewel die skadelike oorbeklemtoning van een aspek van die werklikheid ten koste van die groter geheel.

In hoofstuk 2, "Die idee van die gees", betoog De Beer dat hy in hierdie werk by die oeroue Aristoteliese tradisie van die noëtiese denke aansluit, maar dat dit veral gaan om die betekenis daarvan in die spesifieke tegnologiese en kennisomgewing van ons tyd. Hy haal Hayles oor Morovitz met instemming aan dat ons nou te make het met die "emergence of the mind contemplating the mind" (57). Die gees moet deurlopend geoefen word, en alle wetenskaplike kennis het 'n geestelike dimensie, terwyl sorg en verstaan onlosmaaklik van mekaar is.

In hoofstuk 3 vra hy wat het intussen van die gees geword, 'n soort filosofiese variasie op Proust, à la recherche de l'esprit perdu. Hier vra hy wat word bedoel met die verwerkliking en verwesenliking van die gees met die gees? Dit gaan oor die kultivering van die nous as dit wat verbande trek, en die menslike vermoë tot selfoorskryding. Teen die agtergrond van sy reeds vermelde kritiek op die moderne wetenskap voer hy aan dat die herontwaking van die gees nie van die wetenskap te wagte is nie, maar eerder van die regte milieu:

Die herfundering van die socius en die vestiging van 'n nuwe gemeenskapsgedagte, die stryd teen onkunde en domheid en waaksaamheid oor die ware aard van kennis, die 
herontdekking van taal en omvattende denke teenoor die verheerliking van kwantifisering en die kwantifiseerbare, die skepping van 'n nuwe denke oor die politieke ekonomie van kennis in die rigting van 'n ekonomie van kontribusie ('n bydraende of mededeelsame ekonomie), die herbesinning oor dissiplinariteit in wetenskapwerk met die beklemtoning van die interwetenskaplike, die herformulering van menslike subjektiwiteit in die lig van ontwikkelinge met betrekking tot die posthumane en die kuborg van die kuberkultuur. (84)

Hoofstuk 4 is 'n soort strydskrif vir die gees, oftewel 'n polemologie vir die gees, soos die hoofstuk heet. Hy herinner die leser daaraan dat die magte wat die gees aftakel menslike maaksels is wat hulself as mensreddend aanbied, vernaamlik die industriële populisme in vorme soos die verbruikerisme en die tegnisisme. Die begrip industriële populisme kom van Stiegler, wat voorts ook wys op ongeloof en vertrouensverlies, asook simboliese ellende; sosiopatologie, die verlies aan wete; noëtiese angs; die regressiewe heerskappy van die drifte; dis-individuering en die likwidasie van super-ego deur die drifte in diens van verbruik te stel; en die onvermoë om toekoms te bedink.

De Beer en Stiegler vorder ons op tot 'n stryd om die her-invensie van die gees vir die heropluistering van die wêreld. Ware, moedige denke en konseptuele invensie is nodig. Die hele samelewing behoef terapie, 'n sosioterapie deur kennis, maar dan kennis van 'n spesifieke aard - die transformerende krag van kennis as sosioterapie "is slegs moontlik indien kennis in verhouding tot waarheid, geregtigheid, skoonheid en gevoelvolheid verstaan word" (107).

In hoofstuk 5 word gekyk na die informatisering van die mensbeeld, oftewel die gevare daaraan verbonde om die mens te verstaan aan die hand van 'n eensydige opvatting van inligting. De Beer herinner ons daaraan dat die mens ook gevorm word deur dit wat hy ken. Te midde van die opkoms van verbysterende inligtingstegnologie vra hy wat word van menslike feilbaarheid, lewe en die postbiologiese, bewussynsuiwerheid, die band tussen liggaam en gees, die verhouding tussen taal en rekenaartaal, en die kompleksiteit van kennis? Hy waarsku ons dat hierdie sake nie bedink kan word deur gevorderde tegnologie, oftewel "nie-noëtiese" entiteite nie. Ook waarsku hy ons om versigtig om te gaan met die begrip van die posthumane. Hy spreek hom vir 'n spesifieke verstaan daarvan uit, die einde van die mensbeeld van selfdeursigtigheid en outonomie ten gunste van 'n mensbeeld waar menslike bewussyn deel van 'n dinamieskomplekse geheel is. Hierdie geheel is veral die wêreld waarin ons verkeer, oftewel die samehang en sin van dinge soos deur die mens kollektief verken word. Die wêreld is

veel meer as bloot 'n passiewe plekbepaling, maar 'n aktiewe plekvinding, die invensie van my plek. (Skepping het meer te doen met aktiwiteit met betrekking tot passiewe materiaal; invensie het meer te doen met wedersydse aktiewe intervensie en beweeglikheid en wisselwerking, veral denkmatige wisselwerking en beweeglikheid waaruit daar altyd iets verrassends na vore kom.) (138)

Vervolgens, in hoofstuk 6, word die vraag gevra wat die herbetowering van 'n onttowerde wêreld sal behels. Die samehang van dinge is die sleutelwoord - waar dit geïnventeer word, word die wêreld herbetower; waar dit verloor word, word die wêreld onttower. (Let daarop dat De Beer spesifiek kies vir die woord invensie en nie woorde soos uitvinding of vindingrykheid nie, omdat die woorde volgens hom reeds van betekenis gestroop is.) Hy eien drie fases van wêreldonttowering, naamlik meetbaarmaking, digitalisering, kubernetika en die post-humane. Die geesteswetenskappe het 'n spesiale rol te speel in die herbetowering van die wêreld deur "her-spiritualisering wat beteken om ons terug te bring, weg van die 
onpersoonlike, by die outentieke 'ons-wees', die diepte van gemeenskap, wat verantwoordelik en intelligent met wêreld en met wat in die wêreld is assosieer." (144) En: "Her-opluistering of her-betowering beteken om die rasionaliteit weer binne noëtiese verband terug te bring tot volwaardige redelikheid en komposisionele denkmatigheid." (144)

In hoofstuk 7 val die soeklig op instellings en veral die universiteit in die vraag of instellings nie (meervoudige) denke versmoor/vermoor nie. De Beer waarsku dat akademiese portuurbeoordeling in sy huidige vorm linêere pleks van meervoudige denke begunstig. Daarenteen behoort oorweging aan idees geskenk te word nie net vir die veranderinge wat hulle aan die wêreld maak nie, maar ook aan ander idees (noösfeer). Hier is dit ook belangrik om taal en geletterdheid te herwaardeer as nie blote instrumente nie, maar middele tot die geestelike. Meervoudige denke betrek besinning, verbeelding, fantasie en idees alles as deel van die nous - "om presies uit te kom by die filosofiese vermoë om verbande te soek en te lê, oorskryding van grense te pleeg en iets nuuts te inventeer." (158) So kom ons dan in voeling met die volledige syn soos dit is.

In hoofstuk 8 val die klem op die rol van die geesteswetenskappe in die kultivering en herinvensie van die gees. De Beer wys daarop dat die toekoms van Afrikaans ook afhang van wat kennisgewyse in Afrikaans voortgebring word. Volgens hom is die bedenklike stand van die geesteswetenskappe te wyte aan vier faktore: ekonomiese magte, politieke beleidmakers, 'n kwantitatiewe kennisopvatting, en 'n verskraling van wetenskap tot blote kwantitatiewe en positiwistiese navorsing. So beskryf hy dan die alternatief:

[Die geesteswetenskappe] moet arrogant en vrypostig aandring op die herinvensie van menslike geestelikheid, die herwinning van volle geletterdheid (van lees, skryf en dink), die geveg voer om die verwesenliking van waarheid, die artikulasie van die volle ekologie van kennis verwesenlik en die stryd aanknoop vir menslike sinverwesenliking, waarsonder slegs ondergang wink. (175)

Die gewete wil dat alles in berekening gebring word - ook die onberekenbare, en daar is volgens De Beer 'n spesiale rol wat Afrikaans as gemarginaliseerde taal kan speel in ware geesgerigte transformasie.

Ná hierdie paar hoofstukke oor die gees, kennis en kennisinstellings, val De Beer se fokus in die volgende vier hoofstukke op dringende Suid-Afrikaanse sosio-politieke vraagstukke en die gees. Hoofstuk 8 staan stil by geweld onder die titel "'n Filosofiese besinning oor geweld (Die gees en geweld)". Ofskoon hy saamstem met verskeie denkers soos Ricœur en Girard dat geweld intrinsiek tot menswees is, oordeel hy dat daar in Suid-Afrika 'n aantal aansporinge tot moordende geweld bestaan, soos regeringslui en amptenare se geringskatting daarvan; 'n milieu wat probleemoplossing deur geweld begunstig, geskep deur sowel apartheid as die gewapende stryd; transformasie as vervanging in plaas van geestelike transformasie wat medebestaan bevorder; gewelddadige uitsprake en dreigemente deur mense in gesagsposisies; die opgeëisde reg op die dood van ander om my oogmerke te bereik pleks van die handhawing van lewe; die Westerse doodskultuur; die verobjektivering en reduksie van mense deur kapitalisme en konsumerisme; en die nihilisme.

As oplossings doen hy die volgende aan die hand: Besinning, gesprek, en die gebruik van taal om moord by die naam te noem; die herstel van selfliefde en kollektiewe liefde; korrektiewe informatiseringstrategieë en erkenning van geweld in ons almal en ons kulture met bewustheid van ons gedeelde lotsverbondenheid; sosioterapie as voorwaarde tot psigoterapie, omdat kollektiewe genesing kom voor individuele genesing; die omhelsing van 
die lewe op noëtiese vlak; kollektiewe liefde; en behoorlike regspleging en straf, waarin De Beer nie skroom om subtiel vir die herinstelling van die doodstraf vir moordenaars te vra nie.

In hoofstuk 10 word op verrassend nie-materiële wyse nagedink oor die verband tussen denkontwikkeling en die bestryding van armoede. Volgens De Beer is armoede allereers 'n denkprobleem. Hy wys op die volgende oorsake van die armoedeprobleem: die mensdom se beperkte vermoë tot oplossings; alle mense is arm in die sin dat almal op mekaar teer en mekaar verteer en dit moet erken word om dit te oorstyg. As oplossings pleit hy om 'n lewende ekonomie met 'n bestaanstoelaag vir álmal; vir 'n ingesteldheid daarop om te hê pleks van te wees en 'n klem op geestelike florering; en laastens die ontgin van eie bronne in Afrika om basiese behoeftes vir selfstandigheid te vervul.

In hoofstuk 11 word die gebreke in die Suid-Afrikaanse burger aan die hand van 'n pleidooi vir die "noëties geïnspireerde burger" bepleit. De Beer wys eerstens op die volgende gebreke in die Suid-Afrikaanse demokrasie: slegs 'n klein aantal stemgeregtigde kiesers stem uiteindelik vir die regerende party, die oorstapklousule, swak administrasie, die verskraling van die land se geskiedenis tot die politiek, dat die beste mense selde politici word, en dat mense nie altyd oorwoë stem, terwyl representatiewe demokrasie mense passief maak oor hulle eie lot.

In antwoord hierop vra hy dat groeiende populêre onvergenoegdheid hanteer moet word deur meer inisiatief te neem om menslike potensiaal aan te wend. Vir De Beer is Pierre Lévy se demo-dinamiek, oftewel direkte rekenaarbemiddelde demokrasie van belang, aangesien die internet nuwe soorte menseverhoudinge en politieke potensiaal tot stand bring. Hy is ook bewus van die probleem van ongelykige tegnologiese verspreiding in die land en skryf:

Die vertrekpunt van die mobilisering van die burgery is nie politieke oortuiging nie maar menskundige oortuiging: die intelligensie van almal, die kollektiewe intelligensie van die burgery, ook selfs van die wat nie kan lees of skryf nie - ongeag ras, kultuur, kleur, geslag of ouderdom. (250)

Die vierde van sy politieke hoofstukke, is hoofstuk 12, waarin hy stilstaan by die "invensie/ herinvensie van same-lewing" in Suid-Afrika. Hier wys hy op die noodsaak om geletterdheid in SA te bevorder. Dit sluit in dat kennis gedissemineer moet word, kollektiewe intelligensie, 'n politiek van gemeenskaplike gevoelvolheid wat altyd gereed is vir wat ook al, 'n soort deurlopende kollektiewe bewustheid. Terwyl ons allereers die verlies aan gemeenskap en same-lewing moet erken, moet ons ook vra hoe moet individue lyk wat die same-lewing verwesenlik? Dit gaan om selfstandige individue, selfstandig omdat hulle sowel kollektief as op die persoonlike vlak suksesvol geïndividueer is, oftewel noëtiese selfstandigheid bereik. Sodanige individue kan die eietydse instrumente van mede-bestaan aanwend, naamlik kennis, inligting, intelligente verbruik en digitaliteit.

Einde ten laaste word die boek afgesluit met twee hoofstukke oor taal en toekomsinvensie as deel van die herkultivering van die gees. Hy waarsku opnuut teen die stroping van taal en wys daarop dat die objekte van ware wete my transformeer en my op die weg na mede-bestaan voer. Omdat die toekoms onbeheerbaar is en ons oorkom, pleit hy vir denke as openheid vir die toekoms (meditatiewe of kontemplatiewe denke), waarin inventiewe taalgebruik noodsaaklik is - "respek vir taal in die volheid daarvan en die oorgawe aan die stilte [is] onverbiddelike voorwaardes vir inventiwiteit" (303). Hier moet nie net die filosofie nie, maar ook die poësie en die prosa hulle deel doen. Oplaas is die taak van sulke denkers om te verlig deur in te lig.

Ten slotte: Die krisis van die afwesige gees is 'n kragtige, poëtiese pleidooi vir die gees in ons tyd. Mense van alle oortuigings wat sorg vir die gees dra, het hierin 'n rol te speel. 
Met die voltooiing van my meestersgraad onder De Beer se leiding het hy my aangeraai om nooit tussen die filosofie en die letterkunde te kies nie, maar albei geïntegreerd vir iets meer en beter aan te wend. Daardie iets meer en beter is die herstel van die gees in ons tyd, en in hierdie boek stel hyself die voorbeeld van hoe om dit te doen.

\section{Johann Rossouw}

Departement Filosofie

Universiteit van die Vrystaat

Bloemfontein

rossouwjh@ufs.ac.za 